\title{
Failing the vulnerable: Three new consent norms that will undermine health research with children
}

\author{
A Strode, ${ }^{1}$ BA, LLB, LLM, PhD; M Richter, ${ }^{2}$ BA (Hons), MA, LLM, PhD; M Wallace, ${ }^{3}$ BSoc Sci (Hons), MSc, PhD; \\ J Toohey, ${ }^{4}$ LLB; K Technau, ${ }^{5} \mathrm{MBBCH}, \mathrm{MSc}$ \\ ${ }^{1}$ University of KwaZulu-Natal and HIV/AIDS Vaccines Ethics Group, Durban, South Africa \\ ${ }^{2}$ International Centre for Reproductive Health, Department of Obstetrics and Gynaecology, Ghent University, Belgium; School \\ of Public Health and Family Medicine, University of Cape Town, South Africa; and African Centre for Migration and Society, \\ University of the Witwatersrand, Johannesburg, South Africa \\ ${ }^{3}$ Desmond Tutu HIV Foundation, University of Cape Town, South Africa \\ ${ }^{4}$ HIV/AIDS Vaccines Ethics Group, Durban, South Africa \\ ${ }^{5}$ Empilweni Services and Research Unit, Department of Paediatrics and Child Health, Rahima Moosa Mother and Child Hospital, \\ Faculty of Health Sciences, University of the Witwatersrand, Johannesburg, South Africa
}

Corresponding author: A Strode (strodea@ukzn.ac.za)

\begin{abstract}
The South African National Health Act (No. 61 of 2003) provides a legal framework for the regulation of the health system across the country. Within the Act, section 71 introduces a number of legal norms relating to research or experimentation with human subjects, including research on HIV prevention and treatment. These norms have been criticised for the negative impact they will have on research involving children. This article describes three of the new consent requirements in section 71 of the Act. It shows, using a range of case studies, how important HIV-related research will be halted or undermined if the current provisions are implemented. The article argues that the new consent requirements are out of step with other statutory provisions and ethical guidelines, and as a result they will exclude a large population group - children in diverse settings - from much-needed evidence-based healthcare interventions. The article concludes with a clarion call for support of advocacy on this issue with the Minister of Health and the Health Portfolio Committee.
\end{abstract}

S Afr J HIV Med 2014;15(2):46-49. DOI:10.7196/SAJHIVMED.1014

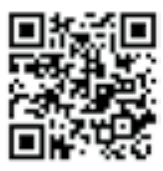

Section 71 of the South African (SA) National Health Act (NHA), ${ }^{[1]}$ which deals with research on or experimentation with human subjects, was put into operation on 1 March 2012..$^{[2]}$ This section fundamentally changes the way in which research with children may be undertaken across the country by introducing highly restrictive and inflexible standards into the current SA ethical-legal framework. ${ }^{[3,4]}$ As a result, it has come under heavy criticism for limiting important research with children and containing impractical and unrealisable provisions. ${ }^{[3-9]}$

The full impact of section 71 has yet to be felt, as very few research ethics committees (RECs) require researchers to comply with its standards. However, this grace period may be coming to an end; on 29 May 2013, draft Regulations Relating to Research on Human Subjects ${ }^{[10]}$ were published for public comment, indicating that the full implementation of section 71 is imminent.

This article focuses on three aspects of section 71, which we believe will have far-reaching consequences for research on children. It shows, using a range of case studies, how important research will be halted or undermined if the current provisions are implemented. The article concludes with a call to support advocacy in law reform.

\section{The importance of health research with children}

There is a global trend towards greater inclusivity in research practices and to facilitate research with children, while recognising that they need to be protected. ${ }^{[12]}$ This approach flows from a recognition of the following:

- The number and severity of diseases that affect children is growing: for example, $17 \%$ of all 15 - 49-year-olds are HIV-positive. ${ }^{[13]}$ Furthermore, mortality among children is unacceptably high, with one out of every ten deaths in the entire population being a child under the age of $14 .^{[14]}$

- Some disorders occur only in children or are more common in children; for example, type 1 diabetes $^{[15]}$ and juvenile rheumatoid arthritis. ${ }^{[16,17]}$

A note on terminology: This article uses the term 'children' to refer to persons under the age of $18 .{ }^{[11]}$ However, the NHA uses the term 'minors' in section 71; therefore, when we refer directly to this section we use 'minors' rather than children. We also limit our discussion to 'health research' on a 'living person', as the regulations in section 71 only apply to these types of studies. 
- The dynamics in some diseases are different in children compared with adults. For example, $20 \%$ of untreated HIV-infected infants will die within 90 days of birth ${ }^{[18]} 40 \%$ within their first year of life, and $52 \%$ by the end of their second year. ${ }^{[19]}$ This type of rapid mortality does not occur among newly infected adults.

- Certain medication has a different impact on children as opposed to adults, as they have differing biokinetics, metabolism, physiology and immunology, and metabolise medicines differently. This results in children needing different dosages, which can only be established through research. ${ }^{[20]}$ Without research, limited information is available on the efficacy and safety of many of the medicines commonly used in children. ${ }^{[20]}$

- There is a developing trend against allowing the licensing of drugs, vaccines and other interventions for children before testing their safety and efficacy in this age group. There is also concern about the 'off label' use of medicines in children. ${ }^{[20]}$

- Using the results from clinical trials on children has resulted in significant health benefits for them. ${ }^{[21]}$ For example, human papilloma virus (HPV) vaccine studies on children have enabled them to receive the vaccine, which can prevent cervical cancer and genital warts. ${ }^{[2]}$

- Laws such as the Children's Act emphasise that children have the right to participate in decision making. ${ }^{[1]}$ Likewise, 'their participation in research is akin to respecting and promoting their entitlement to have their opinions heard. It assumes that they are persons of value, their experiences are of interest to themselves, and to others, and that they have a valuable contribution to make. ${ }^{\cdot[23]}$

Against this backdrop, it is argued that an approach that excludes children from health research, including research related to HIV prevention and treatment, infringes on their constitutional rights to both 'basic health care' and access to 'healthcare services. ${ }^{\text {[24] }}$ For example, their exclusion results in ineffective and even harmful interventions being used owing to the lack of evidence on drug efficacy or dosage. ${ }^{[21]}$ This also has unintended consequences, such as research being delayed or risking lack of funding due to extended enrolment periods that may be required in order to comply with a restrictive legal framework. This may result in research being undertaken in other countries, where the ethical-legal framework is more flexible.

\section{New restrictive regulations for all forms of health research with human subjects}

New standards on health research with children have been introduced, which will limit the circumstances in which they may participate in research. Three of the new consent regulations in section 71 are described and critiqued below.

\section{Requiring written consent}

Section 71 of the NHA provides that research participants must give written, informed consent to health research. ${ }^{[1]}$ This will have serious implications for certain types of health research, such as telephonic interviews and postal or electronic studies, in which the voluntary completion of a questionnaire is commonly regarded as consent. ${ }^{[25]}$ It also excludes the use of passive consent (informing parents of a study and assuming they have agreed to their child participating, unless otherwise instructed) - a practice frequently used with adolescent school-based studies. ${ }^{[9]}$
This approach is out of step with the more flexible approach in the National Health Research Ethics Council (NHREC) guidelines, which provide that consent may be given verbally or in writing. Consent may also, in certain circumstances, be waived, if prior approval of the REC is obtained. ${ }^{[26]}$

\section{Prohibiting independent consent from minors}

The $\mathrm{NHA}^{[1]}$ provides in section 71 that consent must be obtained from parents or legal guardians, and minors if they have understanding. In other words, children under the age of 18 do not have the capacity to consent independently to any form of health research, but they may in certain circumstances provide dual consent alongside that of their parents or guardians.

Mandatory parental consent means that it will no longer be possible to undertake health research where it involves the following

- Certain socially marginalised groups. For example, adolescent men who have sex with men are highly stigmatised in SA, and may face social harms if they are required to seek parental consent to participate in research focusing on their sexuality or sexual practices.

- Behaviour that is legal, but which may incur parental disapproval or reprisal. An example is termination of pregnancy in young girls, as it is likely that very few teenage girls would be willing to approach their parents for consent to a study on a decision they had made autonomously to terminate a pregnancy. Even though this is a lawful decision, studies have confirmed that teenagers will not use such services if they have to obtain parental consent for fear of disapproval. ${ }^{[27]}$

- Illegal behaviours. For example, studies into illegal practices such as child drug use or child prostitution would be complicated by concerns that: (i) children would not be prepared to seek parental consent, or (ii) parents are in fact not available to provide such consent.

- Minimal or no-risk research with children over the age of 12 , using a passive consent approach. ${ }^{[9]}$ For example, this could include completing surveys about drug, alcohol or sexual abuse, eating disorders, attitudes towards oral hygiene, exercise behaviour or even experiences of healthcare provision.

- Orphaned and vulnerable children (OVCs) who do not have parents or legal guardians who are able to consent. This is discussed further below.

It is worth noting that in all of the above examples, the children are likely to be considerably more vulnerable and at risk of ill health than their peers, and research and consequent evidence-based intervention with these groups is particularly pertinent (Table 1).

Prohibiting independent consent from minors is also problematic, in that it conflicts with the consent provisions in the Children's Act, ${ }^{[11]}$ which recognises the evolving capacity of children, and allows them to consent to a range of health interventions before the age of $18 .^{[31]}$ Furthermore, this regulation in the NHA is diametrically opposed to those in the NHREC ethical guidelines, which, for example, allow for independent consent by children in certain circumstances. ${ }^{[26]}$

\section{Limiting the authority to provide proxy consent to parents or legal guardians}

Section 71 of the NHA limits the authority to provide proxy consent to either parents or legal guardians. Generally, parents are the biological 
Table 1. Examples of completed studies that would in the future be difficult to undertake with the requirement of parental/legal guardian consent

Name of study
Ethically approved consent requirements
Reasons why obtaining parental Health benefits to children consent would be difficult or impossible

HIV-related knowledge, attitudes Independent consent and behaviour among SA street youth: reflections on power, sexuality and the autonomous $\operatorname{self}^{[28]}$

A systemic approach to the experiences of adolescents, with regard to terminating their pregnancies $^{[29]}$

Persisting mental-health problems among HIV-orphaned children in $\mathrm{SA}^{[30]}$
Participants aged 13 - 22 years; independent consent obtained
The child research participants were street children living away from adult supervision

The study explored experiences of pregnancy termination. In many cases, participants may not have disclosed their pregnancy or their decision to terminate to their parent/legal guardian. Only 5 of 19 participants had disclosed their pregnancy to their mothers

The mean age of the participants was 13.4 years at the study outset; consent was obtained from participants and caregivers
By definition, participants did not have a parent to provide consent, and it was unlikely that all caregivers would have been designated as legal guardians
Better understanding of the HIV risk of children living on the street

Better understanding of adolescent experiences could inform policy and practice particularly regarding school support and processes, as well as health and community services

The identification of the impact of psychological distress due to AIDS orphanhood over time in comparison with other groups, and highlighting the need for a focus on addressing the specific psychosocial needs of children or adoptive parents of a child, while a guardian is a 'person with guardianship of a child. ${ }^{[11]}$ Unmarried, biological mothers over the age of 18 are automatically the guardian of their child, and in certain circumstances an unmarried father will be a co-guardian. If the biological parents are married, they will be joint guardians. A guardian may also be appointed by the High Court or nominated by a parent in a will. ${ }^{[1]}$ Persons caring for children but not falling into any of the categories above will, in the future, not be able to provide consent for children to participate in health research. This will affect a significant number of children, given that it is estimated that by 2015, 5 700000 children would have lost one or both parents to AIDS. ${ }^{[32]}$

In essence, this means that future studies with children who do not have parents or legal guardians will no longer be possible. Furthermore, such children may not volunteer for health research, as they do not have an adult with the legal authority to provide proxy consent. This principle will also apply to mothers under the age of 18 who have lost parental support but who are at particular risk of both HIV acquisition and transmission. There are also far-reaching implications for research on child-headed households, OVCs and undocumented migrant children. OVCs are increasingly recognised as a special population in terms of HIV risk and transmission, yet they will not be able to inform research. ${ }^{[33]}$ OVC and child-headed households present unique and contemporary issues that must be responded to.

Limiting the authority to provide proxy consent to parents and legal guardians is also out of step with the Children's Act, which recognises that caregivers may consent to certain health interventions such as medical treatment and HIV testing on behalf of children. ${ }^{[34]}$

\section{Conclusions}

Given the principled nature of many of the concerns set out above, we call on the Minister of Health and the Parliamentary Health Portfolio
Committee to address the need for law reform as a matter of urgency. If research institutions are required to comply with these regulations, child research in SA will grind to a halt, and this will ultimately harm the population it purports to protect. Ensuring and supporting rigorous and equitable review by RECs, and promoting clear communication to children and their caregivers during consent and study processes, should be the emphasis of developments in this field rather than restrictive legislation that reduces access to research participation. The nature and form of consent should be driven by the research itself, its benefits, risks, costs and consequences, rather than a blanket one-size-fits-all approach. ${ }^{[25]}$

Acknowledgements. This article is based on a July 2013 submission to the Director General of Health, on the draft Regulation on Human Subjects by the Southern African HIV Clinicians Society. ${ }^{[35]}$ The Society funded a consultative meeting at which many of the points made in the submission were workshopped, and we would like to acknowledge, in particular, the contributions of Kelly Blanchard, Sumaya Mall, Nataly Woollett, Naomi Lince-Deroche, Belinda Alport, Linda-Gail Bekker, Denise Evans and Andy Gray, who all assisted with written input into the final submission. Thanks are also due to Catherine Slack of the HIV/ AIDS Vaccines Ethics Group, University of KwaZulu-Natal, for a critical read of the first draft of this article. The article was in part made possible by funding from the National Institute of Health awarded to the HIV/ AIDS Vaccine Ethics Group via the Desmond Tutu HIV Foundation (DTHF) (1RO1 A1094586) CHAMPS (Choices for Adolescent Methods of Prevention in South Africa). The opinions expressed herein are the views of the authors. They do not represent any position or policy of the NIH.

References

1. South African Government. National Health Act 61 of 2003. Pretoria: Government Printer, 2003. 
2. South African Government. Government Gazette No. 35081, 27 February 2012. Pretoria: Government Printer, 2012.

3. Slack CM, Strode AE, Grant K, et al. Implications of the ethical-legal framework for adolescent HIV vaccine trials: Report of a consultative forum. S Afr Med J 2005;95(9):682-685.

4. Stobie M, Strode AE, Slack CM. The dilemma of enrolling children in HIV vaccine research in South Africa: What is in 'the child's best interests'? In: van Niekerk A Kopelman L, eds. Ethics and AIDS in Africa. Cape Town: David Philip Publishers, 2005:190-207.

5. Strode AE, Slack CM, Wassenaar DR, et al. One step forward, two steps back requiring ministerial approval for all forms of non-therapeutic health research with minors. S Afr Med J 2007;97(3):200-202.

6. Abdool Karim Q, Khamny ABM, Frohlich JA, et al. HIV incidence in young girls in KwaZulu-Natal South Africa - public health imperative for the inclusion in HIV biomedical intervention trials. AIDS Behav 2012;16(7):1870-1876. [http://dx.doi. org/10.1007/s10461-012-0209-y]

7. Pope A. HIV preventative research with minors. SALJ 2007;124(1):167-187.

8. Singh JA, Abdool Karim SS, Abdool Karim Q, et al. Enrolling adolescents in research on HIV and other sensitive issues: Lessons from South Africa. PLoS 2006;2(7):0001-0005. [http://dx.doi.org/10.1371/journal.pmed.0030180]

9. Zuch M, Mason-Jones AJ, Mathews C, Henley L. Changes to the law on consent in South Africa: Implications for school-based adolescent sexual and reproductive health research. Biomed Central 2012;12(3):1-5. [http://dx.doi.org/10.1186/1472-698X-12-3]

10. South African Government. R 378: Regulations Relating to Research on Human Subjects (published for public comment). In: Government Gazette No. 36508, 29 May 2013. Pretoria: Government Printer, 2013.

11. South African Government. Children's Act 38 of 2005. Pretoria: Government Printer, 2005.

12. Fraser S, Lewis, V, Ding S, et al (eds). Doing Research with Children and Young People. London: SAGE, 2004:1-294.

13. Rehle TM, Hallett TB, Shisana O, et al. A decline in new HIV infections in South Africa: Estimating HIV incidence from three national HIV surveys in 2002, 2005 and 2008. PLoS One 2010;5(6):e11094. [http://dx.doi.org/10.1371/journal.pone.0011094]

14. Statistics South Africa. Mortality and Causes of Death in South Africa, 2010: Findings from Death Notification. South Africa: Statistics South Africa, 2013.

15. Maahs DM, West NA, Lawrence JM, et al. Chapter 1: Epidemiology of type 1 diabetes. Endocrinol Metab Clin North Am 2010;39(3):481-497. [http://dx.doi. org/10.1016/j.ecl.2010.05.011]

16. Gabriel SE, Michaud K. Epidemiological studies in incidence, prevalence, mortality, and comorbidity of the rheumatic diseases. Arthritis Res Ther 2009;11:229. [http:// dx.doi.org/10.1186/ar2669]

17. Hahn YS, Kim JG. Pathogenesis and clinical manifestations of juvenile rheumatoid arthritis. Korean J Pediatr 2010;53(11):921-930. [http://dx.doi.org/10.3345/ kjp.2010.53.11.921]

18. Marston M, Becquet R, Zaba B, et al. Net survival of perinatally and postnatally HIV-infected children: A pooled analysis of individual data from sub-Saharan Africa. Int J Epidemiol 2011;40(2):385-396. [http://dx.doi.org/10.1093/ije/dyq255]

19. Obimbo EM, Mbori-Ngacha DA, Ochieng JO, et al. Predictors of early mortality in a cohort of human immunodeficiency virus type 1-infected African children. Pediatr Infect Dis J 2004;23(6):536-543
20. Jaspan HB, Cunniningham CR, Tucker TJB, et al. Inclusion of adolescents in preventive HIV vaccine trials: Public policy and research design at a crossroads. Acquired Immune Defic Syndr 2004;47(1):86-92. [http://dx.doi.org/10.1097/ QAI.0b013e31815d2f27]

21. Caldwell PH. Children in clinical trials. Lancet 2004;364(9436):803-811. [http:// dx.doi.org/10.1016/S0140-6736(04)16942-0]

22. Reisinger KS, Block SL, Lazcano-Ponce E, et al. Safety and persistent immunogenicity of a quadrivalent human papillomavirus type 6,11 , 16, $18 \mathrm{Ll}$ virus-like particle vaccine in preadolescents and adolescents. Pediatr Infect Dis J 2007;26(3):201-209. [http://dx.doi.org/10.1097/01. inf.0000253970.29190.5a]

23. Graham A, Fitzgerald R. Children's participation in research: Some possibilities and constraints in the current Australian research environment. J Sociol 2012;46(2):133-135. [http://dx.doi.org/10.1177/1440783309355065]

24. South African Government. Constitution of the Republic of South Africa, 1996. Pretoria: Government Printer, 1996.

25. Jack CL, Mars M. Informed consent for telemedicine in South Africa: A survey of consent practices among healthcare professionals in Durban, KwaZulu-Natal. S Afr BL 2013;6(2):55-59. [http://dx.doi.org/10.7196/sajbl.287]

26. South African National Department of Health. Ethics in health research: Principles, structures and processes. South Africa: National Department of Health, 2004. www.doh.gov.za (accessed 8 August 2013).

27. Jackson S, Hafemeister TI. Impact of parental consent and notification policies on the decisions of adolescents to be tested for HIV. J Adolesc Health 2001;29(2):85 [http://dx.doi.org/10.1016/S1054-139X(00)00178-6]

28. Swart-Kruger J, Richter LM. AIDS related knowledge, attitudes and behaviour among South African street youth: Reflections on power, sexuality and the autonomous self. Soc Sci Med 1997;45(6):957-966. [http://dx.doi.org/10.1016/ S0277-9536(96)00417-0]

29. De Lange N, Geldenhuys, JL. A systemic approach to adolescents' experiences of terminating their pregnancies. Society in Transition 2001;32(2):246-259. [http:// dx.doi.org/10.1080/21528586.2001.10419045]

30. Cluver LD, Orkin M, Gardner F, et al. Persisting mental health problems among AIDS-orphaned children in South Africa. J Child Psychol Psychiatry 2012;53(4):363-70. [http://dx.doi.org/10.1111/j.1469-7610.2011.02459.x]

31. Strode A, Slack C, Essack Z. Norms for child consent in South African law: Implications for researchers, service providers and policy-makers. S Afr Med J 2010;100(4):247-249.

32. Holborn L, Eddy G. First Steps to Healing the South African Family. SAIRR. Johannesburg: South Africa, 2011

33. Cluver L, Orkin M, Boyes M, Gardner F, et al. Transactional sex amongst AIDSorphaned and AIDS-affected adolescents predicted by abuse and extreme poverty. J Acquir Immune Defic Syndr 2011;58(3):336-343. [http://dx.doi.org/10.1097/ QAI.0b013e31822f0d82]

34. Strode A, Slack C. Using the concept of parental responsibilities and rights to identify adults able to provide proxy consent to child research in South Africa. S Afr J BL 2010;3(2):69-72.

35. Southern African HIV Clinicians Society. Draft Regulation on Human Subjects. http://www.sahivsoc.org/upload/documents/Submission\%20on\%20NHA\%20 Regs_final.pdf (accessed 27 September 2013). 